\title{
Erratum to: Considering total intracranial volume and other nuisance variables in brain voxel based morphometry in idiopathic PD
}

\author{
Samuel Crowley ${ }^{1}$ Haiqing Huang ${ }^{2} \cdot$ Jared Tanner $^{1} \cdot$ Qing Zhao $^{2} \cdot$ Nadine A. Schwab $^{1}$. \\ Loren Hizel $^{1}$ - Daniel Ramon ${ }^{1}$ - Babette Brumback ${ }^{3}$ - Mingzhou Ding ${ }^{2}$. \\ Catherine C. Price ${ }^{1,4}$
}

Published online: 24 March 2017

(C) Springer Science+Business Media New York 2017

Erratum to: Brain Imaging and Behavior (2016)

DOI 10.1007/s11682-016-9656-9

Unfortunately, there's an error in one of the author's name. Qing Zhao was incorrectly spelled as Qing Zho. The original article was corrected.

The online version of the original article can be found at http://dx.doi.10.1007 /s11682-016-9656-9

\footnotetext{
Catherine C. Price

cep23@phhp.ufl.edu

1 Department of Clinical and Health Psychology, University of Florida, 1225 Center Drive, Gainesville, FL 32611, USA

2 Department of Biomedical Engineering, University of Florida, 1275 Center Drive, Gainesville, FL 32611, USA

3 Department of Biostatistics, University of Florida, 2004 Mowry Road, 5th Floor CTRB, Gainesville, FL 32611, USA

4 Clinical and Health Psychology, University of Florida, 101 S. Newell Drive, PO Box 100165, Gainesville, FL 32610, USA
} 